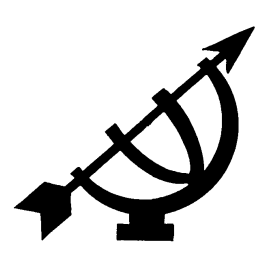

\title{
Die medium van onderrig aan Suid-Afrikaanse universiteite: die geval van Afrikaans
}

\author{
H.P. van Coller
}

Departement Afrikaans \& Nederlands en Moderne Europese Tale Universiteit van die Vrystaat

BLOEMFONTEIN

E-pos: fgvc.rd@mail.uovs.ac.za

The paradox of language and culture is that the universal can only be expressed in a particular manner.

(J.J. Degenaar)

\begin{abstract}
The medium of instruction at South African universities: The case of Afrikaans In this article the focus is on the diminished role of Afrikaans as medium of instruction at South African universities. The tendency world-wide is that governments regard universities as national assets and therefore continuously encroach on what is idealistically termed "academic freedom". In South Africa the ideologically-driven government has targeted education as a strategic terrain and has published several white papers and promulgated as many labour laws with the stress on "redress", "access", "equal opportunities", "recognition of prior learning" and a "uniform qualification system". All these measures are aimed to create one uniform education system and the use of Afrikaans as medium of instruction is clearly seen as detrimental to this august ideal.
\end{abstract}

Opsomming

Die medium van onderrig aan Suid-Afrikaanse universiteite: die geval van Afrikaans

In hierdie artikel is die fokus op die verminderde rol van Afrikaans as medium van onderrig aan Suid-Afrikaanse universiteite. Die neiging wêreldyd is dat regerings universiteite as nasionale bates beskou en gevolglik voortdurend inbreuk maak op wat idealisties "akademiese vryheid" genoem word. In Suid-Afrika het die ideologies gedrewe regering onderwys geteiken as 'n strategiese terrein en verskeie witskrifte gepubli- 
seer en net soveel arbeidswette uitgevaardig wat die klem plaas op "herstel", "toegang", "gelyke geleenthede", "erkenning van voorafgaande onderrig" en genoem word 'n "eenvormige kwalifikasiestelsel". Al hierdie maatreëls is daarop gemik om 'n eenvormige onderwysstelsel te skep en die gebruik van Afrikaans as onderrigmedium word duidelik beskou as skadelik vir hierdie verhewe ideaal.

\section{Inleidende opmerkings: universiteite - 'n historiese perspektief}

Middeleeuse universiteite, en dié wat dagteken uit die vroeë Renaissance, het baie gelyk soos dit wat 'n paar jaar gelede nog as 'n tipiese voorstelling van dié instelling voorgehou sou kon word. Dit was enklaves van geleerdheid waar uitnemende wetenskaplikes gedoseer het aan uitgesoekte studente. Die keuse vir die gebruik van Latyn as wetenskapstaal het reeds die elitêre aard van die universiteit as instelling bevestig: minder ontwikkelde (volks)tale is uitgesluit en ook studente wat nie hierdie taal kon beheers nie. Terwyl hierdie soektog na ware kennis oënskynlik in relatiewe outonomiteit en vryheid kon geskied met marginale aandag aan die breë samelewing, was die mag van 'n doktrinêre Rooms-Katolieke Kerk voelbaar, en kon die aanspraak op wetenskaplike integriteit kwalik totale vryheid waarborg.

Desondanks was universiteitsvestiging nog moontlik en kon weerspannige akademici sonder onoorkomentlike probleme nuwe universiteite stig: die Universiteit van Cambridge (1209) was 'n produk van 'n klomp afstigters van die Universiteit van Oxford, en die Universiteit van Padua dank sy bestaan in 1222 aan 'n klomp dissidente van die Universiteit van Bologna; tewens die eerste Europese universiteit. Vanweë die onderrig in Latyn was mobiliteit van studente selde in die gedrang en was dit afhanklik van eie middele en moontlikhede. Uit die sewentiende-eeuse Nederlandse digter, Constantijn Huygens, se satiriese gedig oor 'n professor kan nog ander ooreenkomste met ons huidige situasie afgelei word: hoogleraars was swak besoldig en het elke geleentheid aangegryp om ekstra geld te verdien.

In latere eeue het die wesensaard van die universiteit as instelling waar kennis geproduseer en oorgedra word, nie drasties verander nie. Wel is die struktuur daarvan gewysig (deur onder andere die insluiting van nuwe dissiplines), veral in die negentiende eeu. Die stigting van die Universiteit van Berlyn (1809) word allerweë beskou as belangrik omdat dit as model gedien het vir verskeie moderne universiteite wat daarna hul beslag gekry het. Waar die Middeleeuse universiteit dienstig was aan die kerk, was die moderne negentiende-eeuse universiteit - ten spyte van die aandrang op akademiese vryheid - 'n produk van nasionale state en 
diensbaar daaraan (ook in die taalmedium daarvan). Daarom het die aanklag dikwels opgeklink dat die universiteit die lakei is van moderne regerings. 1

\section{Akademiese vryheid}

Die ideaal van akademiese vryheid mag lofwaardig wees, maar is in die Suid-Afrikaanse universiteitsgeskiedenis selde indien ooit verwesenlik. Akademiese vryheid word duidelik in die gedrang gebring wanneer inbreuk gemaak word op universiteite se selfbeskikking - en dit raak dikwels die vestigingsfase, befondsing én die toelatingsbeleid. Giliomee (2001a:4; 2001b:39) toon aan dat die aantasting van universitêre outonomie inderwaarheid strek tot by die vestigingsfase van ons SuidAfrikaanse universiteite omdat daar doelbewus getrag is om bestaande universiteite te angliseer en nuwe universiteite as eentalige Engelstalige instellings op te rig.

Die voor die hand liggende voorbeeld van die aantasting van akademiese vryheid is die vorige Nasionale Party-regering se miskenning van die outonomie van universiteite. Miskien die sigbaarste vergryp het die toelating van studente betref. Swart studente is in klein getalle toegelaat tot (Engelse) universiteite omdat daar deur sogenaamde etniese universiteite voorsiening gemaak is vir hul opleiding. Hoewel sommige van hierdie instellings (bv. Fort Hare en die Universiteit van WesKaapland) akademies voortreflik was en omskep is tot bastions teen apartheid, het ander nooit legitimiteit verwerf nie en is hulle gesien as "bush colleges" (kyk ook Viljoen, 1977:185). Teen hierdie agtergrond van staatsinmenging is dit kwalik vreemd dat daar ná 1994 in Suid-Afrika weer 'n situasie aan die ontstaan is waar die regering in diverse verslae en wette (onder andere die South African Qualifications Act, 58 van 1995 en die National Plan for Higher Education, Februarie 2001 en selfs deur die hantering van die Employment Equity Act, 55 van 1998) duidelik te kenne gegee het dat die beplanning van Hoër onderwys een van sy strategiese prioriteite is en dat dit sal geskied in samehang met politieke doelwitte. Giliomee (2001a:30; 2001b:67) wys daarop dat die National Plan for Education wat onlangs bekendgestel is, vergelykbaar is met die aanbevelings van die Van Wyk de Vries-kommissie in 1975: albei is volgens hom verslae wat polities-gedrewe is en geen afwykings of uitsonderings duld nie.

$1 \quad$ In hierdie artikel maak ek dankbaar gebruik van 'n hele reeks artikels gebundel in Fragmente. Tydskrif vir Filosofie en Kultuurkritiek (5 van 2000) oor universiteite, onder andere ljsseling (2000); Goosen (2000) en veral Rossouw (2000). 
Die redes vir die opvallende ooreenkomste tussen die regeerstyl van die ou Nasionale Party en die regerende African National Congress is kompleks en behoef waarskynlik eerder verklaring deur 'n kenner van die staatsleer of eietydse geskiedenis. Opvallend is egter die ooreenkomste wat betref die sentristiese, ideologies-gedrewe manier van regeer, gevoeligheid vir kritiek (veral uit die geledere van hul ondersteuners én van die pers) en 'n toenemende burokratisering in die sin dat elke terrein deur wetlike bepalings bereël moet word.

'n Ander nare gevolg van die uitsluitende aard van die apartheidsjare is dat die uitsluitingsbeginsel (selfs op billike gronde) met wantroue deur die huidige regering bejeën word en dat toeganklikheid op die spits gedryf word (selfs sover gedrewe dat die handjievol Afrikaanse dramas op die nasionale televisie van onderskrifte voorsien moet word). Al hierdie faktore kom deeglik in die spel wanneer gepraat word oor die behoud van, en noodsaak vir, eksklusiewe Afrikaanse opvoedkundige instellings soos skole en universiteite. Voorts lyk dit asof Afrikaans dikwels die sondebok raak vir ware en vermeende sondes van die vorige regering toe Afrikaners hoofsaaklik aan bewind was. Daarop is reeds volledig gewys in talryke publikasies. 'n Oorsig verskyn in Van Rensburg e.a. (1994).

\section{Die ontstaan van Afrikaanse universiteite: 'n kort oorsig}

Alle inrigtings vir Hoër onderwys in Suid-Afrika het tot aan die begin van 1918 Engels as voertaal gehad. Die meeste dosente was Engelstalig en net Engels is vir eksamendoeleindes erken (Steyn, 1994:206). Steyn wys op enkele belangrike gebeure wat die begin aandui van Afrikaanse universiteite: in 1917 word Nederlands toegelaat as eksamenvak en enkele kursusse aan die Victoria Kollege (die latere Universiteit van Stellenbosch) en die Grey Universiteitskollege (die latere Universiteit van die Vrystaat) word ook in "Hollands" aangebied. Die volgende jaar word Afrikaans ook erken as eksamentaal deur die Universiteit van Suid-Afrika en in 1919 ook deur die Universiteit van Kaapstad. Die Potchefstroomse Universiteit was die eerste van die HAU'e wat Afrikaans geword het; in 1919 was dit "bijna uitsluitend" Afrikaans, en in 1920 reeds is alle studente deur medium van Afrikaans opgelei. Steyn (1993b:264) haal aan uit Die Huisgenoot, Oktober 1918 en Die Banier, 25 Maart 1920. In daardie jare is nog hewig verskil oor welke taal Afrikaans of Nederlands naas Engels as akademiese taal gebruik moes word. Afrikaans het spoedig hierdie stryd gewen, veral na die erkenning daarvan as amptelike taal in 1925.

Die veelbewoë geskiedenis van die Afrikaanswording van die Universiteite van Stellenbosch, Pretoria en die (Oranje-) Vrystaat word in be- 
sonderhede behandel deur Steyn (1993a, 1993b, 1994, 1995) en Giliomee (2001b:39-42). In die vroeë dertigerjare het vier instellings Afrikaans en Engels as voertale gebruik: die Universiteit van Kaapstad, die Transvaalse Universiteitskollege (later die universiteit van Pretoria), die Grey-Universiteitskollege (die latere Universiteit van die Vrystaat en die Hugenote-Universiteitskollege. Die Universiteit van Stellenbosch het toe reeds Afrikaans en Nederlands as enigste voertale gebruik. Waar Afrikaans teen die dertigerjare reeds kwyn aan die Universiteit van Kaapstad (Steyn, 1994:214) en dié universiteit later net eentalig Engelstalig geraak het, is die Universiteite van Pretoria en die Oranje-Vrystaat eentalig Afrikaans sodat Suid-Afrika teen 1950 vier Afrikaans- en vier Engelsmedium universiteite gehad het. Ná 1990 begin 'n ommekeer en met die nuwe Grondwet van 1994 verloor Afrikaans geweldig aan status. Dit word nou een van elf amptelike tale en Engels word spoedig nie net lingua franca nie, maar ook voorkeurtaal van die nuwe regering (kyk o.a. Steyn, 1997; Steyn 2000 en Van Coller \& Steyn, 2000).

\section{Die Suid-Afrikaanse universiteit vandag}

Wanneer die universiteit in Suid-Afrika vandag bekyk word, kom terme soos "post-moderne" en post-apartheid-universiteit, "markgedrewenheid" en "globalisering" dadelik na vore. Uit verskeie regeringsverslae en wetgewing oor die hoër onderwys blyk onomstootlik dat die huidige regering 'n veranderde standpunt nahou op die universiteit as instelling. In the New Academic Policy (Discussion Document, Department of Education, November 2001) word dit duidelik gestel dat die postapartheid-konteks 'n reaksie op uitdagings veroorsaak deur globalisering verlang; selfs vereis, maar ook "those arising from the developmental imperatives of equity, redress and reconstruction which derived from the country's history". 'n Post-apartheid beleid en wetlike konteks vir Hoër onderwys word uiteengesit in verskeie verslae en witskrifte. ${ }^{2}$ Dit sou onregverdig wees om hierdie veranderde persepsie bloot te wyt aan die ideologiese gedrewenheid van die ANC; wêreldwyd word daar tans anders na universiteite gekyk (kyk ook Van der Merwe, 1977:38).

2 Van die belangrikste is die SAQA Act (1995), Higher Education White Paper (1995), National Commission on Higher Education Report (1996), White Paper on Higher Education (1997), Higher Education Act (1997), South African Qualifications Authority Act (1998), the National Plan for Higher Education (2001), Proposal for Subsidy Formula (2001), Proposal for Programme Mix (2001) en The Report on the Restructuring of the Higher Education System (2002). 


\section{Toeganklikheid van universiteite}

Universiteite word wêreldwyd gesien as nasionale bates wat primêr in diens staan van die samelewing en uiteraard ook die doelwitte wat 'n bepaalde regering nastreef. Hierdie siening word geëggo deur die huidige regering: "Higher education plays a central role in the social, cultural and economic development of modern societies" (Higher Education White Paper, 1995:1). Omdat universiteite in Suid-Afrika in hoë mate afhanklik is van staatsubsidie (bykans twee-derdes van die lopende kostes word deur die regering betaal), kan hulle nie die regering vervreem nie en word hulle in werklikheid beperk deur wetgewing oor die hoër onderwys. Die huidige regering is sterk ingestel op die bemagtiging en emansipasie van mense; doelstellings wat dikwels gekoppel word aan demokratiese uitgangspunte. Dit word verwoord in stellings dat die transformasie van hoër onderwys verhoogde en breër deelname van studente vereis naas gevoeligheid vir sosiale belange en behoeftes en dat studentetoegang moet verhoog en meer studente moet slaag en uiteindelik gradueer (kyk o.a. in die "Perspective" van die Higher Education White paper en die National Plan for Higher Education, Febr. 2002).

In 'n onlangs gepubliseerde verslag, The Transformation and Reconstruction of the Higher Education System (May 2002), word dit duidelik gestel dat "staff profiles at universities should reflect the demographic composition of South African society". Dit wil lyk asof hierdie verwagting geld vir elke universiteit, ongeag die demografie van die bepaalde provinsie óf die ander aantal universiteite in die bepaalde streek. In die geval van die Universiteit van Stellenbosch (in 'n streek wat 68\% Afrikaanssprekend is en waar daar twee ander Engelstalige universiteite is) is hierdie eise duidelik onregverdig. In 'n vroeëre dokument, Indicators and Benchmarks for Universities and Technicons in South Africa (September 2001), is nasionale mikpunte ("national benchmarks") vir personeelverhoudings en -uitsette net so polities-gedrewe en onrealisties: "At least $40 \%$ of professional staff are African; each gender has $50 \%$ share of contact enrolment" en "at least $40 \%$ of professional staff has $50 \%$ share of professional staff total".

Die toeganklikheid van universiteite het in die afgelope jare 'n twispunt geraak in die geledere van hoër onderwyskundiges omdat dikwels gevoel is dat die verlaging van die toelatingsdrempel (soos in die geval van die Universiteit van Wes-Kaapland) standaarde in die gedrang (kan) bring. Die instel van talle oorbruggingskursusse het ten doel gehad om standaarde te beskerm en om studente deur oorbrugging en ondersteuning op 'n bepaalde akademiese vlak te bring. Hierdie oorbruggingsprogramme het plaasgevind weg van die hoofkampusse en het ook 
hoofsaaklik in Engels plaasgevind, omdat die oorgrote meerderheid kliënte swart studente was, wat vanweë swak onderwys 'n agterstand ontwikkel het. Sodanige leerders het ook hul sekondêre onderwys in Engels gehad en kon slegs in hierdie taal verdere universitêre onderwys geniet. Hierdie model, wat baie verwant is aan die "community college"sisteem van die VSA, het uiteraard die onderrigtaal op die hoofkampus van eentalige Afrikaanse universiteite ${ }^{3}$ onder druk geplaas omdat hierdie studente kwalik hul verdere opleiding nou in 'n ander taal kon volg.

In wetgewing is toenemend voorsiening gemaak "for the recognition of prior learning" en van 'n sekere pariteit wat betref kwalifikasies op bepaalde jaarvlakke; driejarige diplomas is mettertyd vir alle praktiese doeleindes gelykgestel aan driejarige grade. Hierdie toegewing het vir 'n drastiese styging in studentegetalle gesorg, veral uit die geledere van swart studente. Al hierdie stappe tot tot groter toeganklikheid het gehalteversekeringsmaatreëls genoodsaak en taalimplikasies gehad.

\section{Mobiliteit van studente}

In 'n samelewing waar migrasie aan die orde van die dag is, is dit dikwels vir studente onmoontlik om hul studie aan een enkele hoër-onderwysinstelling te voltooi. Twee ander faktore is ook verantwoordelik vir die beweging van studente. Heel dikwels is studente nie in staat om te betaal vir hul hele studietydperk nie; studie word onderbreek en later (dikwels op 'n ander plek) voortgesit. "Legislation which established a single co-ordinated higher education system with different exit levels in academic programmes, ${ }^{4}$ also contributed to 'educational migration'”. Ten einde die mobiliteit van studente te vergemaklik moet programme nie net horisontale mobiliteit toelaat nie; studente moet ideaal gesproke ook in hul voorkeurtaal verder kan studeer. Omdat dit hier primêr oor swart studente gaan, word van regeringskringe 'n hoë premie geplaas op onderrig deur middel van Engels (vgl. die National Plan for Higher Education, February 2001 wat dit duidelik stel dat Afrikaans 'n struikelblok is ten opsigte van toeganklikheid vir baie swart studente). In die jongste dokument oor die transformasie van hoër onderwys (Mei 2002), is die aanbevelings en voorstelle duidelik daarop gemik om eentalige Afrikaanse universiteite deur samesmelting, herstrukturering en dreigemente te vernietig. Terwyl daar om verskeie redes (onder andere

3 Verskeie Histories Afrikaanse Universiteite, die sogenaamde HAU's was enkele jare gelede nog volledig Afrikaans wat onderrig en administrasie betref.

$4 \quad$ Vgl. die South African Qualifications Authority Act, 1995, Act no. 58 of 1995 en die Higher Education Act, Act 101 of 1997. 
ekonomiese realiteite) weinig besware kan wees teen "regional cooperation", kan aspekte van dié voorstelle (soos byvoorbeeld die eenwording van die Randse Afrikaanse Universiteit met Wits Technicon - terwyl die Engelstalige Universiteit van die Witwatersrand byna langsaan geleë is) kwalik anders gesien word as politieke ingenieurswese.

\section{Pragmatiese eise}

Gekonfronteer met groot werkloosheid (veral onder swart mense), en gestu deur die drang tot regstellende aksie, sien die regering die heil vir hul mense dikwels in die hoër onderwys. Hoewel technikons en tegniese kolleges primêr die taak het om geskoolde mense pasklaar vir die beroepsmark te lewer, het universiteite ook nie die eis om beroepskoling vrygespring nie. Daar word toenemend klem geplaas op die leeruitkomste van akademiese programme met die verwagting dat daar naas kennis ook vaardighede by leerders tuisgebring moet word. "Implementeerbaarheid" en "relevansie" hou nie net verband met die uitkomste van onderrigprogramme nie; dit word toenemend toegepas op navorsing. Die implikasie is dat navorsers al hoe meer alliansies aangaan met die sogenaamde private sektor wat dikwels ook die opdraggewers van navorsing is. Weens die oorheersende aard van Engels in die openbare sfeer en die feit dat regeringsinstansies vrywel net in Engels funksioneer, word navorsing toenemend (ook in die Geesteswetenskappe) in Engels gedoen. Die eis om multidissiplinêre navorsing word al dringender en gepaardgaande daarmee veral die opleiding en begeleiding van swart navorsers. In albei gevalle impliseer dit gewoonlik dat die navorsing in Engels geskied. Implikasies vir die voertaal van universiteite (veral op nagraadse vlak) spreek vanself.

\section{Internasionalisering en globalisering}

Enersyds weens onkeerbare globaliserende tendense, andersyds vanweë die noodsaak wat daar vir universiteite bestaan vir internasionale deelname, erkenning en samewerking, raak wetenskapsbeoefening in Engels 'n noodsaak vir wetenskaplikes in kleiner tale. Salverda (2001) wys op die situasie in die tersiêre sektor in Nederland wat volgens hom kommer baar, omdat Nederlands binne die afsienbare toekoms daar as onderrigtaal mag verdwyn. Nie net publikasies (in veral die Natuurwetenskappe) is toenemend net in Engels nie; nagraadse studie vind bykans eksklusief in Engels plaas en navorsingsaansoeke aan die National Research Foundation moet ook in dié taal geskied. Weens dié tendense gaan stemme dikwels op - ook van Afrikaanssprekendes - dat die oorskakeling na Engelse onderrig studente beter voorberei vir kompetisie in 'n domein waar Engels die lingua franca is. Dit is duidelik dat die regering een doel voor oë het en dit is om Suid-Afrikaanse 
hoëronderwysinstellings (en hul studente) kompeterend te maak in wat bekend staan as "the global economy".

\section{Betrokkenheid by die samelewing}

Tradisioneel is universiteite as kennissentra gesien waar kennis geproduseer en oorgedra is. Daarin het ook hul primêre nut vir die samelewing gelê. Die bekende voorbeeld van Newton wat sy eksperimente met swaartekrag voortgesit het, skynbaar onbewus van en onaangeraak deur die pes-epidemie elders in Engeland, is altyd gebruik om die begrip "nut vir die gemeenskap" te relativeer. Wie het dan die meeste tot voordeel van die gemeenskap bygedra, is altyd gevra: Newton of diegene wat die pes aktief bestry het? Plek vir retoriese vrae is daar nie meer nie. In Suid-Afrika bestaan die konsep "nasionale universiteite" (soos Oxford en Cambridge kwalik). Universiteite word toenemend gesien as gemeenskapsverankerd en dit beteken óók die onmiddellikomringende gemeenskap.

Gemeenskapsdiens word nie meer gesien as 'n patroniserende gebaar aan die gemeenskap nie; die legitimiteit van universiteite self is op die spel. Toenemend word gepraat van gemeenskapsdiensleer omdat dit impliseer dat ook studente betrokke moet raak by gemeenskapsdiens en dat 'n simbiotiese verhouding tussen gemeenskap en universiteit tot stand moet kom. Tot redelik onlangs het gemeenskapsdiens primêr in Engels plaasgevind omdat daar 'n toespitsing op benadeelde swart gemeenskappe was en aanvaar is dat hul Engels verkies. Vanselfsprekend kan dit ook in Afrikaans geskied waar die gemeenskap dié taal magtig is. By my eie universiteit (die Universiteit van die Vrystaat) word sodanige aksies toenemend (ook) in Sesotho onderneem en dit is moontlik die tendens vir die toekoms.

\section{Die universiteit as ekonomiese entiteit}

Dat universitêre opleiding altyd 'n sosiaal-ekonomiese voordeel ingehou het, naas 'n akademiese, behoef weinig bewyse. Omgekeerd is die universiteit natuurlik ook 'n ekonomiese bate vir die gemeenskap en die staat en kan baie van sy navorsingsprodukte (soos patente, uitvindings en prossesse) aangewend word tot direkte voordeel van die breëre gemeenskap. Goed opgeleide persone dra uiteraard ook by tot ekonomiese welvaartskepping.

Die hedendaagse universiteit word veelal bedryf as ekonomiese (eerder as akademiese instelling) en rig hom in baie opsigte op die mark; en dit is opvallend hoeveel rektore en viserektore van Suid-Afrikaanse universiteite geskoolde ekonome is. Entrepreneuriese aksies van universi- 
teite word nie net aangemoedig nie, maar selfs afgedwing deurdat staatsubsidies toenemend afgeskaal word. Om die sogenaamde "derde geldstroom" te tap, vra aksies wat veel verder gaan as tradisionele fondswerwing. Dit lei tot afhanklikheid van die privaatsektor wat veelal sake slegs in Engels doen: "Wiens brood men eet ...".

In die afgelope jare het die studentetal aan universiteite drasties verander. Daar was 'n enorme styging van studente (56 000 meer) by die Histories Afrikaanse Universiteite (HAU'e) en tegelykertyd 'n daling van studentegetalle (ongeveer 27000 minder) by Histories Swart Universiteite (HSU'e). Streng gesproke, kan dit gesien word as 'n gesonde ekonomiese beginsel waar markkragte dikteer (kyk Du Plessis, 2001:24 vir getalle). Alle universiteite het egter nie dieselfde ontwikkelingsvlak bereik nie en kan nie op gelyke vlak meeding nie. Dit is daarom duidelik dat die hele proses deur ' $n$ nasionale beplanningsraamwerk gereguleer moet word soos ook inderdaad gebeur het deur die voorgestelde nasionale plan vir hoër onderwys wat ook ten doel het om meer gegradueerdes te lewer ten einde die ekonomie te laat groei.

\section{Die universiteit en ideologie}

Daar is vroeër reeds geredeneer dat universiteite selde totaal los van ideologiese paradigmas kon funksioneer; ook nie in die Suid-Afrikaanse verband nie. Ons huidige situasie is geen uitsondering nie. Binne die ANC-regering se denke wat toeganklikheid tot universiteite wil verhoog en 'n broertjie dood het aan enige vorm van uitsluiting, is die konsep van eksklusief-Afrikaanse universiteite onaanvaarbaar. In talle van die uitsprake van minister Kader Asmal kom die verwyt na vore dat die Universiteit van Stellenbosch, byvoorbeeld, mense uitsluit as gevolg van die feit dat hulle nie Afrikaans kan verstaan nie. Dat Engelse universiteite dieselfde doen ten opsigte van Afrikaanssprekendes word nie as 'n geldige argument aanvaar nie, omdat Afrikaanssprekende studente wel Engels kan verstaan. Dat dit dalk hul tweede taal is of dat hulle dit dalk swak hanteer, word gesien as ongeldig: swart studente verkeer meestal in dieselfde posisie.

Die nasionale plan vir hoër onderwys laat hom duidelik uit oor "equity" en "redress". Een van die sterkste ideologiese ingrype in die universiteitsoutonomie is die Employment Equity Act (no. 55 of 1998). Terwyl die toelating van swart studente 'n hoë prioriteit was, geld dié wet die samestelling van die werkerskorps. Die getal mense uit die "aangewese groepe" (waar duidelik onderskei word tussen mense anders as blank, vroue en gestremdes) moet verhoog word om meer verteenwoordigend te raak. Gereelde terugvoer moet per kategorie geskied, planne tot verhoging van persentasies uit die aangewese groepe moet voorgelê 
word en kwalifikasies is nie meer die deurslaggewende faktor nie potensiaal word 'n belangrike kriterium. Die ideale wat deur hierdie wet gepropageer word, lyk lofwaardig (byvoorbeeld die bewerkstelliging van gelykheid in die werkplek deur "promoting the constitutional right of equity and the exercise of true democracy" en voorts "to eliminate unfair discrimination in employmnent" (p. 2008).

Daar is egter verskeie probleme wat dit moeilik uitvoerbaar maak, en selfs weerstand tot gevolg het: die gebrek aan geskoolde persone op bepaalde terreine, onrealistiese tydskale en teikens en die sogenaamde "institusionele kulture" van histories Afrikaanse universiteite. Swart dosente (wat dikwels wêreldwyd gewerf word), kan nie Afrikaans praat nie en derhalwe ook nie in dié taal doseer nie. Verpligte aanstelling van diesulkes beteken derhalwe verengelsing. Ook in parallelmediumuniversiteite veroorsaak hierdie wet 'n krisis omdat eentalige swart dosente net kan klasgee aan Engelssprekende (oorwegend swart studente), met die gepaardgaande verwyte van ghettovorming en die instandhouding van apartheidstrukture.

\section{Die status quo wat Afrikaanse universiteite betref}

In die lig van bostaande opmerkings is dit duidelik dat eksklusiewe Afrikaanse universiteite nie meer 'n haalbare opsie is nie. Selfs as gedink word aan 'n virtuele of tegnologiese universiteit, sal eksklusiwiteit ten opsigte van taal nie oorweeg kan word nie. Daarvoor was die inpak van globalisering te groot en raak universiteite wat hul studente nie kan oplei om internasionaal te kompeteer nie, irrelevant. Handboeke in bepaalde dissiplines (soos Fisika) kan slegs in Engels voorgeskryf word omdat nuwes elke ses maande verskyn en dit nie in Afrikaans op so 'n kort termyn bygewerk kan word nie. Dit sal dus nooit vir 'n Afrikaanssprekende student moontlik wees om (soos in die geval van sy Engelssprekende medelandsburger) sy opleiding in een taal te ontvang nie.

Die konsep van eksklusief-Afrikaanse universiteite behoort nie op tafel geplaas te word nie. Inderwaarheid bestaan daar ook tans geen eksklusief-Afrikaanse universiteit nie. Die hoofkampus van die Potchefstroomse Universiteit vir Christelike Hoër Onderwys kom waarskynlik die naaste hieraan, hoewel dié universiteit in die geheel dit nie is nie en die Vanderbijlpark-kampus ook anders bemark word. Die Universiteit van Stellenbosch noem homself Afrikaans, maar dit geld eerder sy administrasie en voorgraadse kursusse op die Stellenbosch-kampus. Kursusse soos Bosbou en Krygskunde, wat nie elders gedoseer word nie, word gedoseer in Engels, terwyl voorgraadse kursusse in Bellville ook in Engels en talle nagraadse kursusse op Stellenbosch slegs in Engels gedoseer word. 
Ook die Vrystaatse Universiteit is steeds parallelmedium. Die enigste uitsondering is die MBA-kursus en die Bachelor in Management Leadership wat net in Engels aangebied word. Die inkorporering van die kampusse van die Engelstalige Universiteite van Qwaqwa en Vista in Bloemfontein spel egter gevaar vir Afrikaans. Die Randse Afrikaanse Universiteit is tans nog parallelmedium, maar indien die voorgestelde samesmeltings plaasvind, sal dit onmiddellik verengels. Ook die Universiteit van Pretoria is onder ' $n$ angliserende topstruktuur vinnig besig om te verengels. Giliomee en Schlemmer (2001:29) wys daarop dat die Universiteit van Pretoria in sy voorleggings met die oog op die National Plan for Higher Education geen verbintenis ten opsigte van Afrikaans of parallelmediumonderrig aandui nie. Uitlatings van die rektor van UP aan dr. Saleem Badat wys daarop dat hulle die oorgang na "one predominant formal academic language" gretig afwag. Voeg daarby dat die UP ook "al universiteit [is] wat nie 'n respons op die Alexander-komitee se vraeboog oor veeltaligheid ingestuur het nie". (Giliomee \& Schlemmer, 2001:30). Dan dui alles daarop dat daar reeds 'n keuse ten gunste van Engels gemaak is.

Uit onderhoude met die vorige rektor, prof. J. van Zyl blyk dat in sy lys van doelwitstellings vir die Universiteit van Pretoria, die behoud van Afrikaans (en 'n Christelike karakter) nie eers figureer nie. In die missieformulering van dié universiteit word dit duidelik gestel dat internasionale posisionering prioriteit geniet, saam met "plaaslike relevansie". Oënskynlik het dit met taalwerklikhede (dat dit die residensiële universiteit met die grootste groep ingeskrewe Afrikaanssprekende studente is - meer as 16000 ) min te make.

Despite the fact that this university also (and sometimes exclusively) uses English as medium of instruction (cf. Shlemmer \& Giliomee 2001: 119 ) it has been severely criticized by the National Working Group for its lack of transformation. In 2000 only $6 \%$ of the university's permanent academic staff members were black (Strydom, 2002:7).

Hoewel ek my om praktiese redes (en omdat ek geen kenner is van die technikonwese nie) beperk tot universiteite, sou ek verwag dat dieselfde patroon sigbaar is by die vyftien technikons en die groot aantal tegniese kolleges. Eksklusief-Afrikaanse opvoedkundige instellings raak skaars. Selfs skole wat vroeër Afrikaans was, verengels in so 'n mate dat $60 \%$ van skole in die Gauteng-gebied tans parallelmedium-onderrig aanbied.

Die vraag moet dus liefs anders geformuleer word: hoe kan Afrikaanse onderrig behou word in die tersiêre onderwyssektor, en veral dan aan universiteite? 


\section{Waarom Afrikaanse universiteite?}

$\mathrm{Na}$ my gevoel kan hierdie vraag uit ten minste drie perspektiewe of fokushoeke bekyk word: die reg van kulturele minderhede of die demokratiese fokus; die belang wat dit inhou vir die taal en sy funksies self - die taal-sosiologiese fokus; en die bydrae wat sodanige instellings vir die land kan inhou, met ander woorde die pragmatiese fokus.

Wat die demokratiese vraagstelling betref, kan gekyk word na 'n omvattende korpus tekste oor liberaal-demokratiese beginsels. Ek verwys in hierdie verband na 'n verklaring, The Rights of Minorities (2001: 13), wat deur die Friedrich-Naumann-Stiftung (Stigting) uitgereik is. Daarin word duidelik uiteengesit dat nasionale minderhede die reg het op onderwys en opleiding in hul eie taal tot op tersiêre vlak, mits getalle dit regverdig. Gesien die dalende aantal Afrikaanssprekende matrikulante en studente, spreek dit vanself dat dit Afrikaansonderrig regverdig op 'n regionale basis. Binne taalverspreidingspatrone beteken dit konkreet opleiding in die suide van die land, waar Afrikaans selfs in 'n meerderheidsposisie is, die Gauteng-gebied, waar Afrikaans sterk staan en die sentrale landsdele soos die Vrystaat en Noordkaap waar daar 'n oorheersend Afrikaanse taalkleur bestaan, ten spyte daarvan dat moedertaalsprekers van Afrikaans min is. $\mathbf{5}$

Demokratiese oorwegings impliseer terselfdertyd ook die bemagtiging van mense en tale: sonder die uitsig op hoër onderwys in 'n spesifieke taal, verdwyn die noodsaak vir sekondêre onderwys in die taal en word persone genoop om later in hul tweede of derde tale verder te studeer. Veral in koloniale gebiede in Afrika ly mense steeds aan die gevolge hiervan. Demokratiese oorwegings kan selde van demografiese aspekte geskei word. Weens demografiese oorwegings is daar in die meerderheid veeltalige lande eentalige universiteite in bepaalde gebiede (vgl. Loubser, 2001:90). Hiervolgens is die Wes-Kaap geregtig op selfs meer as die huidige een hoofsaaklik Afrikaanse universiteit.

Uit taal-sosiologiese hoek kan gestel word dat 'n taal nooit volwaardige draer van die behoeftes van sy sprekers kan wees sonder dat dit alle funksies vervul nie. Die akademies-wetenskaplike funksies is in hierdie verband belangrik, soos om taal te wees van die politiek, die regswese, die media en die universiteit. In die twintigste eeu is baie kundigheid en energie gewy aan juis die bereiking van hierdie ideaal vir Afrikaans. In

5 Du Plessis (2001) gee 'n duidelike beeld van die getalle sprekers van Suid-Afrikaanse tale, taalgeografie en 'n opvoedkundige profiel en ekonomiese bydraes volgens taalgroepering. 
dié verband kan terloops verwys word na akademici van wêreldgehalte wat hul lewens gewy het aan die uitbouing van Afrikaans met die gepaardgaande onvermoë om hul eie akademiese ideale in internasionale verband uit te bou. Vir Afrikaans en sy funkies sou die verlies aan wetenskaplike funksies en status verreikende gevolge hê. Dit sou skole noop om verder te verengels en kan inderwaarheid die begin van die einde van Afrikaans se hoër funksies beteken.

Die ideale van Afrikaanssprekendes om hul taal se wetenskaplike funksies te behou, sou dalk as selfsugtig getipeer kon word. Tog behoort gekyk te word na die voordele wat dit ook vir Suid-Afrika as geheel inhou. Daar is van vroeg af (reeds sedert 1917) geleentheid gebied aan Afrikaanssprekendes om hul skoling in hul eie taal te ontvang of om wetenskaplik besig te kon wees in Afrikaans. Hierdie geleentheid is met albei hande aangegryp en Afrikaanssprekendes (en mense wat in dié taal gestudeer en gewerk het), het in die vorige eeu 'n enorme bydrae tot die land gelewer. Daar is bykans nie een terrein waar die bydraes gering was nie, maar sonder die bydraes in die besonder van 'n Hendrik van der Bijl, Anton Rupert, Elize Botha, Merwe Scholtz, Herman Giliomee, die Stokers en Wally Grant, om maar net enkeles te noem, sou Suid-Afrika oneindig armer gewees het.

Weens onder andere die taalverwantskap het veral Afrikaanse universiteite bande met Nederlandse en Vlaamse universiteite wat dagteken uit die beginjare van die vorige eeu. Hierdie ander, Europese tradisie, beteken 'n ander soort wetenskapsbeoefening en wetenskaplike paradigma wat veral in bepaalde dissiplines (taal- en literatuurwetenskap, filosofie, die regte en historiografie) 'n wesenlike bydrae gelewer het tot wetenskapsbeoefening hier te lande.

Hierdie Europese verbintenis vind ook dikwels neerslag in uitruilooreenkomste en ander vorme van wetenskaplike samewerking, wat dikwels ook finansiële voordele inhou. ' $\mathrm{n}$ Voor die hand liggende voorbeeld is die groot skenkings van die Nederlandse regering en Vlaamse deelregering aan bemagtigingsprojekte (veral ten aansien van meertaligheid) hier te lande. Die grootste voordeel is egter dat hierdie uitruilooreenkomste ook geleentheid bied vir die opleiding van SuidAfrikaners oorsee, wat die kundigheidsvlak van Suid-Afrikaners verhoog, met enorme voordele op die langtermyn vir ál die inwoners hier te lande.

\section{Hoe moet die ideale Afrikaanse universiteit lyk en hoeveel moet daar wees?}

'n Maklike antwoord is dat daar geen ideaaltipe van die Afrikaanse universiteit bestaan of gepostuleer kan word nie, omdat universiteite 
radikaal van mekaar verskil op grond van geskiedenis en tradisie, die aard van studente, geografiese situering en eiesoortige missies en visies. Volgens Du Plessis (2001) se stel statistiese kriteria, wat onder andere kyk na die bestaande aantal skoolverlaters, ingeskrewe studente, die totale persentasie van die bevolking, ensovoorts, is Afrikaanssprekendes geregtig op tussen 2,7 en 7,8 residensiële universiteite. Die Universiteit van Stellenbosch is 'n Afrikaanse universiteit in die WesKaap waar Afrikaanssprekendes dominant is (Afrikaanssprekendes maak ongeveer $62 \%$ uit van dié provinsie se inwoners) en waar daar nog twee ander universiteite is wat in Engels doseer. Die Universiteit van die Vrystaat is gesitueer in die middel van die land waar Afrikaans 'n dominante taal is, maar waar dit as huistaal maar klein is en waar swart skoliere (wat verreweg in die meerderheid is) hul skoolopleiding in Engels ontvang. Boonop moet hierdie universiteit waarskynlik met drie ander Engelssprekende kampusse (Qwaqwa en die twee Vistakampusse) amalgameer. Waar eentalige Afrikaanse onderrig in die een geval billik en haalbaar is, is dit in die tweede ondenkbaar.

Ek sou liefs die bestaande vyf universiteite waar Afrikaans nog as onderrigtaal gebruik word, wou sien as 'n kritiese massa wat nie verder afgeskaal behoort te word nie.

Onderling sou daar 'n duidelike onderskeid getref kon word tussen:

- 'n Afrikaanse universiteit wat óók in Engels klasgee in sekere spesialisasierigtings en op nagraadse vlak.

- 'n Afrikaanse universiteit wat as geheel doseer in albei tale, maar wat op sy hoofkampus oorheersend Afrikaans is en op sy sub-kampus, oorheersend Engels. Studierigtings wat op net een van die kampusse aangebied word, sal op parallelmediumwyse aangebied word.

- 'n Afrikaanse universiteit wat 'n parallelmedium doseer, verbind is tot meertaligheid en waarvan die admininistrasie in twee tale sal geskied.

- 'n Tweetalige universiteit waarvan die administrasie in twee tale sal geskied en op parallemediumwyse onderrig gegee word in Afrikaans en Engels.

Hoewel ek nie graag bestaande universiteite met een van bostaande modelle wil verbind nie, is dit gebiedend noodsaaklik dat Afrikaanse onderrig wetlik verskans word op al die kampusse (ook deur middel van kwotastelsels) en veral by die Universiteit van Pretoria. Hoewel ek graag hierdie universiteit sou wou sien as Afrikaanse universiteit wat in albei tale doseer, lyk selfs die model van dié universiteit as 'n parallelmediuminstelling tans te optimisties. Dit wil eerder voorkom asof dié universiteit homself sien as Engelse universiteit wat (op korttermyn en op 
beperkte wyse, byvoorbeeld in die beginstudiejare) nog voorsiening maak vir onderrig in Afrikaans.

Prof. Andreas van Wyk het gelyk as hy die gevare verbonde aan parallelmediumonderrig uitwys (Van Wyk, 2001:4). ${ }^{6}$ Dit is ook so dat dit maklik aanleiding kan gee tot twee verskillende universiteite op dieselfde kampus. Waar daar geen alternatief is nie (soos by die Universiteit van die Vrystaat), is parallelmedium-onderrig die beste oplossing, maar daar moet gewaak word teen "ghettovorming". Minister Kader Asmal het al in 1999 (Beeld, 20-11) 'n hou gemik na diegene wat hy as seperatiste bestempel het. Geskeide koshuise by Kovsies wat telkens uitgewys is as 'n verskansing van apartheid, was inderwaarheid ' $n$ keuse van alle studente wat neerkom op 'n keuse vir kultuureie koshuise. Dit neem egter nie die verantwoordelikheid van sodanige universiteite weg om ghettovorming op kreatiewe wyse teen te werk deur gemeenskaplike waardes te ontwikkel deur middel van opedae en ander gesamentlike projekte, kulturele kruisbestuiwing, ensovoorts. In die geval van parallelmedium-instellings loop die kleiner taal altyd die gevaar om verswelg te word deur die groter taal. Die regering sal daarom deur wetlike bepalings die regte van minderheidstale by so 'n universiteit moet help verskans.

Prof. Van Wyk se voorkeur vir dubbeltaligheid (bo parallelmedium) is egter onbegryplik, omdat dit totaal onprakties is waar (en dit is bykans orals in Suid-Afrika die geval) dosente en studente nie albei tale kan gebruik nie. Wat in die praktyk gebeur, is dat daar oorgeslaan word na die taal wat deur almal begryp word. Dit sal nooit Afrikaans wees nie. Parallelmedium-onderrig, onderhewig aan streng bepalings, is veel beter as dubbelmedium-onderrig in dieselfde klaslokaal (soos skynbaar by Stellenbosch gebeur) of ten opsigte van seleksies van vakke of kursusinhoude. Dié sisteem bied ook 'n maklike oorgang na eentalige onderrig soos inderdaad aan die Universiteit van Port Elizabeth gebeur het.

Die Afrikaanssprekende gemeenskap kan dus volgens alle aanvaarde begrippe van billikheid aandring op ten minste die behoud van die status quo: twee hoofsaaklik Afrikaanse universiteite en drie ander waar Afrikaans steeds onderrig sal word op alle vlakke. In die praktyk beteken dit dat daar slegs aan twee universiteite beperkte toegang/deelname sal wees vir persone wat nie Afrikaanssprekend is nie (en dan ook net in 'n uiters geringe mate). Gesien die aantal sprekers van Afrikaans, is so 'n verdeling persentasiegewys geensins onbillik nie. Hierdie situasie moet noem tweetalige onderwys slegs 'n oorgangsfase "wat in die langer termyn die kleiner taal assimileer en as medium van onderrig uitwis" (p. 12). 
wetlik verskans word. Dit moet duidelik gestel word dat so 'n versoek geensins 'n terugkeer na apartheid suggereer nie; die persone wat die ergste gekniehalter word deur eentalig Engelse universiteite, is bruin plattelandse Afrikaanssprekendes wat ook die laagste persentasie deelname aan die hoër onderwys het (Giliomee \& Schlemmer, 2001: 121).

Uitsprake van minister Asmal dat daar 'n einde gaan kom aan "eksklusief-Afrikaanse universiteite" is wyd gerapporteer (kyk Volksblad, 7 November 2002: "Geen universiteit nét Afrikaans"). Daar was ook ontsteltenis by baie rolspelers oor hierdie ingryp in die outonomie van die univerisiteite. 'n Polemiek rondom die US-taaltaakspan se voorstelle oor die voertale van die Universiteit van Stellenbosch, het eweneens wye reaksies ontlok (kyk Die Burger, 8 Oktober 2002 na Herman Giliomee se kritiek). Dit is duidelik dat die belange en voortbestaan van Afrikaans as kultuurtaal op die spel is. Rektore van die HAU'e is enersyds huiwerig om die regering wat die geldbeursie dra, te vervreem. Andersyds raak internasionalisering so 'n dwingende kwessie dat skynbaar gevoel word dat 'n keuse vir slegs (of hoofsaaklik Afrikaans) veral op nagraadse vlak dié ideaal gaan kniehalter. Uit tendense oorsee (veral in Nederland) is dit duidelik dat 'n eenvormige kwalifikasiestruktuur in Eeuropa en die vrye beweging van studente Engels bevoordeel. By verskeie Nederlandse universiteite (o.a. Leiden en Groningen) bestaan al 'n uitgebreide aanbod van Engelstalige studieprogramme. ' $n$ Goeie beheer van Engels raak in Europa en oor die hele wêreld 'n sleutel tot beroepsukses. Dit is daarom nie vreemd nie dat stemme in Nederland toenemend opgaan dat skole ook tweetalig (Nederlands en Engels) moet raak ten einde studente vroeg reeds vaardig in Engels te maak. Die situasie in Suid-Afrika is daarom kwalik uniek: kleiner (en selfs groot) tale word toenemend bedreig deur die wêreldwye tendens tot anglisering. Kom daar nie georganiseerde reaksie hierteen nie, staar ons 'n nuwe Middeleeue in die gesig waar één taal ander tale oorheers en oligargieë en magsklieke direk bevoordeel word.

\section{Bibliografie}

DU PLESSIS, Bertie. 2001. Toepassing van universiteite volgens onderrigtaal: demografiese, ekonomiese en onderwysdata. (In Giliomee, H. \& Schlemmer, L. Kruispad. Die toekoms van Afrikaans as openbare taal. Kaapstad: Tafelberg. p. 15-33.)

GILIOMEE, Herman. 2001a. Die taal- en kulturele uitdagings van die historiese Afrikaanse universiteite in Suid-Afrika. Twintigste D.F. Malherbe-gedenklesing, 19 April 2001. Bloemfontein : Universiteit van die Vrystaat.

GILIOMEE, H. 20001b. Die taal- en kulturele uitdagings van die histories Afrikaanse universiteite. (In Giliomee, H. \& Schlemmer, L. Kruispad. Die toekoms van Afrikaans as openbare taal. Kaapstad : Tafelberg. p. 34-75.) 
GILIOMEE, H. \& SCHLEMMER, L. 2001. Kruispad. Die toekoms van Afrikaans as openbare taal. Kaapstad : Tafelberg.

GOOSEN, Danie. 2000. Die postmoderne universiteit: enkele spekulatiewe notas. Fragmente. Tydskrif vir Filosofie en Kultuurkritiek, 5:21-30.

IJSSELING, Samuel. 2000. Filosofie, politiek en universiteit. Fragmente. Tydskrif vir Filosofie en Kultuurkritiek, 5:11-19.

LOUBSER, Max. 2001. Afrikaans as regstaal. (In Giliomee, H. \& Schlemmer, L. Kruispad. Die toekoms van Afrikaans as openbare taal. Kaapstad: Tafelberg. p. 76-93.)

The Right of Minorities. 2001. A Declaration of Liberal Democratic Principles concerning Ethnocultural and National Minorities and Indigenous Peoples. Liberales Institut der Friedrich-Naumann-Stiftung.

ROSSOUW, Hennie. 2000. Die toekoms van die universiteit. Fragmente. Tydskrif vir Filosofie en Kultuurkritiek, 5:56-76.

SALVERDA, Renier. 2001. Ons Erfdeel. 44(1):3-10, Jan.-Feb.

STEYN, J.C. 1993a. Die taalstryd aan die Grey Universiteitskollege ten tyde van die rektoraat van D.F. Malherbe. Acta Academica, 25(4):87-117.

STEYN, J.C. 1993b. Die voertaalvraagstuk aan die Suid-Afrikaanse universiteite tot ongeveer 1930. South African Journal for Linguistics. Supplementum, 18.

STEYN, J.C. 1994. Vroeë pleidooie vir 'n tweetalige Universiteit van Kaapstad. (In Van der Merwe, Chris, Waher, Hester \& Hambidge, Joan. Rondom Roy. Studies opgedra aan Roy Pheiffer. Kaapstad : Department Afrikaans en Nederlands, Universiteit van Kaapstad. p. 205-216.)

STEYN, J.C. 1995. 'n Rektor skors sy voorganger - 'n onstuimige hoofstuk uit die taalstryd aan die UKOVS. Journal for Contemporary History, 20(1):87-112.

STEYN, J.C. 1997. Die posisie van Afrikaans as voertaal en die vak Afrikaans en Nederlands aan universiteite. Tydskrif vir Geesteswetenskappe, 37(1):236-247.

STEYN, J.C. 2000. 'n Pluriforme model vir die behoud van Afrikaans as voertaal aan universiteite. Tydskrif vir Geesteswetenskappe, 40(1):48-58.

STRYDOM, A.H. 2002. Equity at the University of the Free State: National benchmarks and experiences of other universities. Julie 2002. Ongepubliseerde referaat gelewer tydens universitêre byeenkoms.

VAN COLLER, H.P. \& STEYN, J.C. 2000. Van Wyk Louw en Leipoldt. Twee verteenwoordigende denkrigtings oor die geskiedenis en toekoms van Afrikaans. Tydskrif vir Geesteswetenskappe, 40(2):153-164.

VAN DER MERWE, H.W. \& WELSH, D. 1977. The future of the university in Southern Africa. Cape Town : David Phillip.

VAN RENSBURG, F.I.J., MALHERBE, E.F.J. \& LANDMAN, K.J.H., reds. 1994. Taalverskuiwing sedert 1994. Die prosesse van bevoorregting, ontmagtiging en verwaarlosing. Ongepubliseerde studiestuk. Johannesburg : RAU.

VAN WYK, Andreas. 2001. Afrikaans in ons hoër onderwys in die jaar 2001. Gesprek by KKNK, 9 April 2001.

VILJOEN, G. 1977. The Afrikaans universities and particularism. (In Van der Merwe, H.W. \& Welsh, D. The future of the university in Southern Africa. Cape Town : David Phillip. p. 172-187.)

\section{Wette en verslae}

Discussion document, Department of Education (November 2001)

Employment Equity Act (no. 55 of 1998)

Higher Education Act (Act 101 of 1997)

Higher Education White Paper: 1 
Higher Education White Paper (1995)

Indicators and Benchmarks for Universities and Technikons in South Africa (September 2001)

South African Qualifications Authority Act (Act no. 58 of 1995)

South African Qualifications Authority Act (1998)

The Transformation and Reconstruction of the Higher Education System (May 2002)

National Commission on Higher Education Report (1996)

National Plan for Higher Education (2002)

Proposal for Programme Mix (2001)

Proposal for Subsidy Formula (2001)

Report on the Restructuring of the Higher Education System (2002)

White Paper on Higher Education (1997)

\section{Kernbegrippe:}

Afrikaans as voertaal by universiteite hoër-onderwys-beleid taalbeleid taaldebat

\section{Key concepts:}

Afrikaans as medium of instruction at universities higher education policy language debate language policy 
